\title{
Educação feminina e fé: - Colégio dos Santos Anjos e o Rio de Janeiro da Belle Époque (1898-1920)
}

\author{
Women's education and faith: \\ the Colégio dos Santos Anjos and the Belle Époque \\ Rio de Janeiro (1898-1920)
}

Giselle Pereira Nicolau

\section{Resumo}

A pesquisa analisa a educação confessional feminina, a partir da chegada da Congregação dos Santos Anjos ao Brasil, em 1893. O país, que sentia os ecos da reforma ultramontana, iniciada em meados do século XIX, se abriu para as influências propagadas por Roma, com vistas a reordenar o catolicismo brasileiro, sob a perspectiva da Igreja Tridentina. Nessa direção, uma das ações preconizadas por esse movimento foi a criação de instituições de ensino voltadas para a formação de mulheres. Tal processo foi estimulado pelas elites que, observando os impactos da modernidade, respaldaram a implementação dessas escolas no país, a fim de preparar as jovens moças para desempenhar na sociedade a função de mãe e esposa, e em determinados casos religiosas. Buscando analisar este contexto, o artigo tem por objetivo compreender a relação entre instrução e fé, a partir da criação do Colégio dos Santos Anjos, no Rio de Janeiro da Belle Époque, entre os anos de 1898-1920.

Palavras-chaves: História das Mulheres. Educação. Rio de Janeiro. 


\begin{abstract}
The research analyzes women's confessional education, in the context of the Congregação dos Santos Anjos arrival in Brazil in 1893. The country, which felt the echoes of the mid $19^{\text {th }}$ century ultramontane reform, opened up to the influences propagated by Rome with a view to reordering Brazilian Catholicism from the perspective of the Tridentine Church. In this direction, one of the actions advocated by this movement was the creation of educational institutions aimed at educating women. This process was stimulated by the elites who, observing the impacts of modernity, supported the implementation of these schools in the country, in order to prepare young girls to play the role of mother and wife in society, and in certain cases, to became nuns. Seeking to analyze this context, the article aims to understand the relationship between education and faith, from the creation of Colégio dos Santos Anjos, in the Belle Époque Rio de Janeiro, between 1898 and 1920.
\end{abstract}

Keywords: Women's history. Education. Rio de Janeiro.

\title{
Introdução
}

A relação entre religiosidade e educação no Brasil remonta aos primórdios da colonização. Empenhados na instrução e divulgação da fé católica no Novo Mundo, os membros da Companhia de Jesus foram os precursores na implantação de uma estrutura educacional na colônia, entre os anos de 1549-1759, quando foram expulsos por ação das reformas empreendidas pelo Marquês de Pombal. Desta forma, o binômio fé e ensino, cedeu espaço para uma pedagogia mais laicizada, segundo o espírito iluminista da época, e a serviço do Estado.

No século XIX, após a emancipação política, a constituição de 1824 veio reforçar, por meio do padroado, a relação entre Estado e Igreja. Assim, o catolicismo ficou reconhecido como religião oficial do Brasil, cuja autoridade era exercida pelo Imperador, que aprovava clérigos e bispos, nomeados pelo pontífice. Seguindo essa lógica, os membros do clero eram funcionários do governo e, portanto, estavam submissos aos interesses imperiais. ${ }^{1}$

\footnotetext{
${ }^{1}$ Cumpre destacar que, de um modo geral, essa regra valia para os membros do clero diocesano, uma vez que o clero religioso estava vinculado às ordens religiosas.
} 
No tocante à educação neste momento, verificou-se que não havia diretrizes que contemplassem a toda população brasileira, de modo que o acesso às escolas ficava restrito aos membros das elites. Embora houvesse alguns esforços na criação de espaços educacionais, por meio da implementação do método lancasteriano, ${ }^{2} \mathrm{o}$ qual eximia a presença do professor e reduzia os gastos educacionais, existia uma série de obstáculos de ordem econômica e política que inviabilizaram esse projeto. Através da lei de número 16, sancionada em agosto de 1834, o governo brasileiro procurou se isentar de sua responsabilidade para com o ensino primário e secundário, deixando-os ao encargo dos poderes provinciais. Através dessa medida descentralizadora, e em sintonia com os ventos do liberalismo, o compromisso do Estado para com o sistema educacional era transferido para outras iniciativas. ${ }^{3}$

A partir da segunda metade dos oitocentos, a fé católica brasileira experimentava uma aproximação com Roma, ao mesmo tempo em que buscava sua autonomia frente ao poder imperial. O ultramontanismo no Brasil constitui-se no esforço de organizar a Igreja no país, segundo os ditames do Concílio de Trento; postulava uma fé mais centralizada na autoridade dos clérigos e nos sacramentos, especialmente da eucaristia e da confissão. Além desses aspectos, o processo de romanização do catolicismo brasileiro estimulou a mensagem do evangelho, por meio da catequese, buscando combater as práticas populares no seio da religiosidade católica, as quais eram propagadas, na visão dos prelados, pelas irmandades e confrarias.

Em conformidade com a reforma ultramontana, houve um processo de feminização no interior da cristandade. A mulher, sempre associada à docilidade e subserviência, ao assumir a sua condição de mãe e esposa exemplar, deveria gerar futuras vocações para a Igreja, constituindo-se em propagadora da doutrina e dos ideais cristãos emanados pelo concílio. Foi no bojo deste mesmo processo de reafirmação do feminino pelo catolicismo, que as congregações voltadas para as mulheres tiveram uma sobrevida. As ordens religiosas femininas, que outrora eram direcionadas fundamentalmente para uma vida ascética, a partir da segunda metade do século XIX passaram a assumir um carisma apostólico, atuando nos campos da educação, dirigindo ou lecionando em escolas, e da saúde, no cuidado com os enfermos; assim como em asilos e orfanatos.

\footnotetext{
${ }^{2}$ Segundo o método lancasteriano, os alunos deveriam ser instruídos por um monitor, isto é, um estudante com conhecimento superior aos demais aprendizes que, sob a supervisão do professor, ensinaria de maneira rápida e qualitativa os conteúdos.

${ }^{3}$ MANOEL, I. A., Igreja e educação feminina, p. 21-23.
} 
Na década de 1850, por exemplo, a cidade do Rio de Janeiro recebeu a Congregação Filhas da Caridade, ordem religiosa francesa que, por ação do governo imperial, inaugurou o Colégio da Imaculada Conceição. A educação feminina à época era voltada para a formação de jovens esposas, afeitas aos serviços manuais e domésticos, e que recebiam base nas doutrinas cristãs e humanísticas. Embora este seja um caso isolado, é somente nas últimas décadas dos oitocentos, que ocorre o florescimento de iniciativas religiosas no campo da educação. Tal projeto constituiu-se em uma ação promovida pela Igreja Católica e das oligarquias ${ }^{4}$ políticas, que em um contexto de redimensionamento da fé no Velho Mundo, possibilitou a vinda de ordens religiosas estrangeiras para o país. Aberto às influências culturais e intelectuais francesas, o Brasil criou condições para o estabelecimento desses espaços, por meio de iniciativas que se concretizaram apenas no período republicano, a exemplo do Colégio Notre Dame de Sion e o Sacré Coeur de Jésu.

Aofinal dos oitocentos, oRiode Janeirovinha perdendoconsideravelmente o seu prestígio econômico, embora se mantivesse como sede do poder político no Brasil. Concomitantemente, o regime republicano atravessava uma série de sobressaltos que dificultaram o seu processo de enraizamento. Com efeito, foi apenas em 1898, sob a presidência de Campos Sales, que a República se consolidou, por meio da adoção da política dos governadores, um acordo que privilegiava as elites estaduais. A este período, que se estendeu até 1920, foi denominado pela historiografia brasileira de Belle Époque, momento de estabilidade para o governo federal junto às suas oligarquias, de progresso material e desenvolvimento cultural para o país. De acordo com Jeffrey Needell, as elites cariocas buscavam se diferenciar social e culturalmente em relação às demais classes sociais, ao criar um sentimento de continuidade aristocrática, ao promover e defender seus interesses, que as legitimavam perante a sociedade. ${ }^{5}$

É nesse contexto de valorização do ensino confessional feminino e de Belle Époque, que foi fundada na freguesia do Engenho Velho, ano de 1893, a Congregação dos Santos Anjos.

\footnotetext{
${ }^{4}$ Cristalizado nas ciências humanas e sociais, o conceito de oligarquia é utilizado para denominar um segmento social que possui poder econômico e projeção política. Ainda, segundo a historiografia, o período compreendido entre os anos de 1894-1930 é designado como República oligárquica. CARDOSO, F. H., O sistema oligárquico nos primeiros anos da República, p. 17-57.

${ }^{5}$ NEEDELL, J., Belle époque tropical, p. 11.
} 


\section{As razões da partida e o Brasil como solução}

A Congregação dos Santos Anjos surgiu na cidade de Lons-le-Saunier, no departamento de Jura, na França, em 15 de outubro de 1831, por iniciativa de Barbe-Elise Poux, a qual adotou o onomástico de Mère Marie Saint-Michel. Logo no momento de sua fundação, a ordem adotou como serviço a educação para jovens de classe média.

Neste contexto, a Europa, e em especial a França, viviam um período de crescente laicização, originada nos processos revolucionários do final do século XVIII e início do século XIX. Em 1830, pouco antes da fundação da congregação, a França vira a queda de Carlos X e o malogro de seu projeto de restauração do Antigo Regime. Conforme dito anteriormente na introdução, a Igreja católica buscava reafirmar seu poder, defendendo a centralização de suas estruturas, o direito divino dos monarcas, bem como a hierarquização da sociedade, por meio de uma onda conservadora denominada ultramontanismo.

O desejo de frear o ímpeto liberal na Europa tivera curta duração neste século XIX. As congregações religiosas que haviam surgido neste período de restauração política, enfrentaram os desafios impostos pelo governo francês, especialmente em relação às medidas educacionais de laicização do ensino, propostas pelo presidente Jules Grévy. A Congregação dos Santos Anjos logo sentiu os efeitos desse processo, que valorizava o ensino público nos liceus, em detrimento das escolas confessionais. " "Em razão da forte pressão contrária de parte das leis civis e laicas então dominantes" " no território francês, a alternativa encontrada para a vigência da ordem foi o Brasil.

Superiora à época, Mère Elizabeth Marie, estabeleceu contato com um padre francês que se encontrava no Rio de Janeiro. Tratava-se do Padre Louis Blondet, capelão da Santa Casa de Misericórdia, o qual apresentou para a religiosa as possibilidades que havia no campo da educação feminina na cidade, em correspondência datada de outubro de 1891. Segundo o presbítero, "aqui, em obras de educação, há as Irmãs de São Vicente de Paulo, que são muito ignorantes. Há as Damas de Sion, do Sagrado Coração. Os Colégios delas estão cheios. Não há lugar para nenhuma criança, em todos eles". ${ }^{8}$ Reforçando $\mathrm{o}$ argumento de que a cidade oferecia um horizonte promissor para o estabe-

\footnotetext{
${ }^{6}$ MAYEUR, J.-M., Les débuts de la IIIe République (1871-1898), p. 114.

${ }^{7}$ JORNAL DO COMMERCIO, Rio de Janeiro, 14 jun. 1993, p. 4.

${ }^{8}$ BLONDET, P. L., Carta para Mère Elizabeth, 10 out. 1891.
} 
lecimento de uma instituição de ensino, Blondet asseverou que tanto as irmãs de Sion quanto as vicentinas faziam "fortunas colossais", 9 dada a procura por uma instrução de qualidade pelas elites cariocas.

Para Ivan Manoel, a educação das jovens moças até as últimas décadas dos oitocentos era muito voltada para a formação de esposas aplicadas ao serviço doméstico e demais atividades artesanais. ${ }^{10}$ Tal panorama se modificou à medida em que novas exigências se impuseram em relação à instrução feminina, como o domínio da escrita e da leitura, conhecimentos gerais. Por essa razão, a aliança entre as oligarquias e a Igreja católica atendia aos anseios por um ensino sólido e confessional.

Se por um lado foi possível verificar a ação entre oligarquias e Igreja, que representada pelos prelados, convidavam as ordens religiosas para a fundação de colégios voltados para a educação feminina, a Congregação dos Santos Anjos trilhou um caminho distinto, vindo para o Brasil por conta própria. Certamente, o auxílio do já mencionado Padre Blondet foi indispensável para o estabelecimento das freiras no Rio de Janeiro. Foi o religioso que apresentou as condições para a instalação de uma sede na cidade, buscando possíveis patrocinadores para a obra religiosa, além de intermediar junto ao bispo da diocese a permissão para a fundação de uma casa na então capital federal.

\section{Os preparativos para a vinda: correspondências e "escritas de si"}

O conjunto de correspondências trocadas entre o Padre Blondet e a Mère Elizabeth Marie, nos anos de 1891 e 1893, revelam os bastidores desta empreitada. Em concordância com Ângela de Castro Gomes, as cartas, para além de uma troca de mensagens, é uma forma de escrita de si, em que se veiculam informações pessoais. ${ }^{11}$ Envolve a dimensão mnemônica, individual e coletiva, e, portanto, possui valor de fonte histórica, pois anuncia sujeitos portadores de verdade; indivíduos comuns em detrimento das figuras de relevo na sociedade. Cumpre destacar que a documentação epistolar está inserida em um contexto histórico, e revela dimensões socioculturais, políticas e econômicas.

Assim, em correspondência endereçada à Mère Elizabeth, datada de 14 de dezembro de 1891, Padre Blondet, o qual ficara responsável por encontrar um benfeitor para a obra religiosa, revelou mudança nos planos. "Aquele que, me

\footnotetext{
${ }^{9}$ BLONDET, P. L., Carta para Mère Elizabeth, 10 out. 1891.

${ }^{10}$ MANOEL, I. A., O início da educação católica feminina no Brasil (1859-1919), p. 115-134.

${ }^{11}$ GOMES, A. C. (Org)., Escrita de si, escrita da história.
} 
parece, o bom Deus havia determinado, a favor de vocês está prestes a perder toda a fortuna", ${ }^{12}$ destacou o religioso. Pretendendo contactar o presidente e o principal acionista da Companhia Geral das Estradas de Ferro, o Conde de Leopoldina, Blondet que se mantinha informado pela imprensa, soube que seus negócios estavam prestes a falir. Por meio de uma explicação pormenorizada a respeito da desvalorização das ações da empresa na bolsa de valores, $o$ presbítero aludiu ao contexto de crise econômica da época, provocada pelo encilhamento. A segunda opção, no entanto, seria o Conde de Figueiredo, que se encontrava na Europa. Outro nome cogitado foi o do banqueiro Mayrinck, "que poderia facilmente instalar" as freiras, se o "câmbio" não estivesse "muito baixo". Mas os ânimos políticos estavam muito exaltados, por conta da posse do Marechal Floriano Peixoto, que governou o país sob forte convulsão social, provocada pela Revolta da Armada (1892-1893) e a "de uma nova província, o Rio Grande do Sul", referindo-se à Revolta Federalista. ${ }^{13}$

A despeito do cenário turbulento que caracterizou os primeiros anos do regime republicano, e que fora descrito em algumas das correspondências, ele não impediu Padre Blondet de lograr êxito junto ao Conde de Figueiredo, o qual beneficiou a Congregação dos Santos Anjos. Em 15 de outubro de 1892, por exemplo, o religioso em missiva para Irmã Elizabeth noticiava que o Senhor Copertino do Amaral, Diretor do Ministério do Interior, havia obtido licença para abrir uma escola, assim como a "despensa dos exames exigidos por lei". ${ }^{14}$ Apresentou, ainda, um projeto no qual deseja se empenhar no dia seguinte à redação da carta: "construir um comitê de senhoras, as mais ricas da Tijuca", que assinariam um documento solicitando ao bispo Dom José Pereira da Silva Barros, que estabelecesse no mesmo bairro um colégio católico dirigido pelas irmãs francesas. ${ }^{15}$

É importante ressaltar que a ação dessas senhoras, a qual fora liderada por Emília Serpa, irmã do Conde de Figueiredo, reforçava a importância da presença da congregação na cidade. O parecer favorável da parte da Igreja iria de encontro aos anseios do próprio bispo, o qual era um continuador da reforma protagonizada por Dom Pedro Maria de Lacerda, em favor do ordenamento da diocese de São Sebastião do Rio de Janeiro. De acordo com o prelado, a vinda de congregações "são muito úteis" para a vida religiosa da capital da

\footnotetext{
${ }^{12}$ BLONDET, P. L., Carta para Mère Elizabeth, 14 dez. 1891.

${ }^{13}$ BLONDET, P. L., Carta para Mère Elizabeth, 14 dez. 1891.

${ }^{14}$ BLONDET, P. L., Carta para Mère Elizabeth, 15 out. 1892.

${ }^{15}$ BLONDET, P. L., Carta para Mère Elizabeth, 15 out. 1892.
} 
República, no "santo intuito de propagar a instrucção à infância e proteger os desamparados". A permissão para o projeto se deu "com o maior entusiasmo", por parte do bispo, que ainda se comprometeu em tratá-las como "filhas muito queridas". ${ }^{16}$ Sugeriu que se formasse um comitê de mantenedoras da obra religiosa, a fim de poder auxiliar as freiras no aluguel e nas despesas de maiores necessidades, conforme observado em correspondência de Blondet para a superiora geral, Mère Adelaide Condamin. ${ }^{17}$

Os preparativos para a chegada da congregação dependiam de um elemento essencial: o local onde as freiras se instalariam. Por meio da leitura das correspondências de Padre Blondet para a superiora geral, observou-se que as religiosas estabeleceriam o colégio em propriedade de aluguel muito custoso, que pertencia ao Barão de Andarahy. Havia um acordo nominal, de que o imóvel estaria à disposição da congregação, a partir de dezembro de 1892. Contudo, o mesmo não fora cumprido, visto que a "Condessa de Andarahy tem ainda os seus móveis no palácio. Não quer retirá-los, antes de encontrar uma casa que lhe convenha". ${ }^{18}$ Diante desse impasse, foi preciso buscar um outro espaço, já que a notícia da chegada das irmãs e a fundação do Colégio dos Santos Anjos ocupavam as páginas dos jornais de época. Assim, o palacete do Conselheiro João Pedreira do Couto Ferraz, situado no Andaraí, foi a solução encontrada para a congregação.

\section{A Congregação dos Santos Anjos no Rio de Janeiro da Belle Époque}

A partida das irmãs da Congregação dos Santos Anjos foi acordada para o mês de maio de 1893. Ainda que, a missão no Brasil tivesse sido idealizada por Ir. Elizabeth, a madre veio a falecer, às vésperas da viagem, com uma "congestão pulmonar". Contudo, a morte da religiosa não impediu que este projeto fosse levado adiante. Dessa maneira, saíram da França as religiosas que compuseram o primeiro quadro de gestoras do colégio. Assim, Mère Saint Bernard André foi encarregada de ocupar a função de superiora, Ir. Marie Ludovica Palais, diretora educacional, Ir. Louise de Gonzague Rath, Ir. Marie Célestine Christophe, Ir. Marie Alicia, a qual ficou encarregada de lecionar desenho, Ir. Leónie Gauthier

\footnotetext{
${ }^{16}$ Livro de Registros de Offertas em favor das obras das Irmãs dos Santos Anjos, p. 2, 1893. Álbum n ${ }^{\circ}$ 1/A, Centro de Memória Santos Anjos, Colégio dos Santos Anjos - Rio de Janeiro.

${ }^{17}$ BLONDET, P. L., Carta para Mère Adelaide Condamin, 17 jan. 1893.

${ }^{18}$ BLONDET, P. L., Carta para Mère Adelaide Condamin, 20 jan. 1893.
} 
e Ir. Marie Agathe Palais, responsável pela cozinha escolar. Vieram também leigas para atuarem no ofício de educadoras, como Mlle. Marguerite Lavenier e Mlle. Vanier, que assumiria a cadeira de desenho e pintura. ${ }^{19}$

A viagem para o Brasil teve duração de vinte e dois dias. As religiosas partiram de trem de Macôn para Bordeaux, onde pegaram o vapor Portugal, que fez escalas nas cidades de Lisboa, Dakar, na costa africana, Pernambuco e Bahia, chegando ao Rio de Janeiro na noite de 25 de maio de 1893. A cidade que as acolhia, experimentava uma série de transformações urbanas, já desde a fase final do período imperial. O surgimento de novos bairros, a partir da incorporação de linhas de bonde e de trem, e a adoção de medidas de higienização do espaço público, ${ }^{20}$ não isentaram a capital federal de problemas relacionados à infraestrutura, saneamento e às famigeradas epidemias, que vez ou outra assolavam os moradores. Inclusive, foi em um desses surtos que atingiu Ir. Agathe Goillard, levando - a óbito, e poucos dias depois a Ir. Marie Ludovica Palais. ${ }^{21}$

Somada a essas questões, a transferência do bispo Dom José para outra diocese, o não cumprimento dos auxílios prometidos pelo comitê, além dos problemas enfrentados pela fase inicial do regime republicano, constituíramse em obstáculos para a consolidação da Congregação dos Santos Anjos no Brasil. Além desses problemas, as religiosas se depararam com outra realidade: a quantidade de alunas. Isso porque as correspondências trocadas com Padre Blondet eram repletas de otimismo. Acreditava que, uma vez instaladas teriam muitas alunas, "de 30 a 40 alunas na chegada", podendo chegar a "100, no decorrer do ano". 22

A despeito das expectativas que havia em relação à quantidade de aprendizes, havia certa divulgação do trabalho de excelência que era desenvolvido pelas irmãs da Congregação. O periódico $O$ Paiz de 24 de agosto de 1893, por exemplo, publicou um texto intitulado "Educação da juventude", de autoria do Reverendo Padre Senna Freitas, em que recomendava "aos pais de família" o "recente Colégio dos Santos Anjos". Buscando reforçar a seriedade da instituição, o religioso destacou que a fundação de "uma casa destas não é

\footnotetext{
${ }^{19}$ JORNAL DA FUNDAÇÃO da Comunidade de Santos Anjos no Rio de Janeiro. Santos Anjos no Rio de Janeiro: preparação e ano de 1893, Volume 01-B, Centro de Memória Santos Anjos, Colégio dos Santos Anjos - Rio de Janeiro.

${ }^{20}$ RODRIGUES, A. E. M. R., A costura da cidade, p. 84.

${ }^{21}$ JORNAL DA FUNDAÇÃO da Comunidade de Santos Anjos no Rio de Janeiro. Santos Anjos no Rio de Janeiro: preparação e ano de 1893, Volume 01-B, Centro de Memória Santos Anjos, Colégio dos Santos Anjos - Rio de Janeiro.

22 BLONDET, P. L., Carta para Mère Adelaide Condamin, 10 fev. 1893.
} 
uma simples empresa especulativa, mas a realização prática de um sacerdócio educativo", que "oferece sempre uma ótima garantia para aqueles que confiam cuidados estranhos esses pedaços da sua alma que se chamam os seus próprios filhos". ${ }^{23}$ Certamente, em uma cidade como o Rio de Janeiro, que culturalmente se espelhava na França, como um modelo de refinamento e civilização, ter mais uma instituição inspirada nos valores educacionais europeus atendia aos anseios das elites carioca. Dessa forma, dentre as inúmeras qualidades conferidas às religiosas, destacava-se a formação diferenciada em que cada uma delas possuía, "um diploma oficial de professora", que conferia "o direito de ensinar em qualquer escola normal de França". Em outras palavras, o autor do texto revelava a elevada qualificação das educadoras, que eram habilitadas a formarem novas profissionais da educação. De acordo com o narrador, a professora que lecionava desenho era "tão notável que alguns de seus quadros a óleo já foram expostos no estrangeiro, em salões de exposição". Completa afirmando que a "educação que ali se ministra, compreende não só a física e a intelectual, como também a moral e a religiosa", destacando o espírito de doação que é empregado "todos os dias e a todas as horas na educação da juventude do sexo feminino. (...) garantia oferecida aos pais de família”. ${ }^{24}$

Embora a documentação hemerográfica tenha indicado o Colégio dos Santos Anjos como uma instituição dedicada exclusivamente ao ensino de jovens moças, constatou-se que até 1898 predominou o ensino misto, atendendo aos meninos e meninas do Rio de Janeiro. Porém, com o passar dos anos, se consolidou um formato de ensino voltado apenas para o público infantil feminino, passando a funcionar nos regimes de internato, semi-internato e externato. ${ }^{25}$ Cabia à instituição imprimir à índole das alunas, os valores morais e religiosos do catolicismo, por meio da "prática das virtudes, do conhecimento de verdades religiosas e da assimilação dos bons exemplos preservados pela história". ${ }^{26}$

Em relação à formação das educandas, foi possível compreender que o ensino era dividido em três etapas. A primeira delas era o curso preparatório, que oferecia um ensino preliminar, composto por noções de cálculo, catecismo, polidez, leitura, escrita, língua francesa, bem como de trabalhos manuais. A

${ }^{23}$ FREITAS, Rev. Pe. S. F., O Paiz, Rio de Janeiro, 24 ago. 1893, p. 2.

${ }^{24}$ FREITAS, Rev. Pe. S. F., O Paiz, Rio de Janeiro, 24 ago. 1893. p. 2.

${ }^{25}$ Devido à procura pelo ensino confessional no Brasil, a Congregação dos Santos Anjos inaugurou colégios em Juiz de Fora e Varginha, em Minas Gerais, bem como em São Paulo. Ver: JORNAL DO COMMERCIO, Rio de Janeiro, 14 jun. 1993, p. 4.

${ }^{26}$ MANOEL, I. A., O início da educação católica feminina no Brasil (1859-1919), p. 14. 
segunda etapa, por sua vez, era constituída pelo curso elementar, em que era ensinado história do Brasil, geografia, português, leitura, declamação, francês, cálculo, trabalhos manuais, desenho, piano e polidez. Por fim, o curso médio encerrava este ciclo instrução, reforçando por meio das mesmas cadeiras oferecidas nos cursos anteriores, com o acréscimo de aritmética, gramática francesa, ortografia portuguesa e a instrução religiosa, a qual compreendia o conhecimento das sagradas escrituras e o catecismo.

Aformação intelectual das alunas era acompanhada por uma série de estímulos e avaliações diárias de comportamento e "deveres clássicos; os testemunhos de satisfação distribuídos cada semana; a inscrição no quadro de honra exposto na sala de visita"; o aconselhamento dado pelas educadoras e madre superiora; além das "composições mensais", dos exames trimestrais e de final de ano. Sobre esses últimos, vale ressaltar que se tratava de solenidades públicas, presenciada por membros do clero, autoridades de revelo para a sociedade e pelos familiares das discentes. Após os exames, as aprendizes costumavam fazer apresentações e exposições, demonstrando para a comunidade escolar todo aprendizado adquirido ao longo do ano letivo. As alunas de melhor rendimento recebiam premiações, de acordo com as notas que recebiam em cada disciplina.

Essa estrutura de ensino, no entanto, se manteve até junho de 1900, quando se modificou o currículo escolar. $\mathrm{O}$ curso preparatório era integrado pelas cadeiras de cálculo, leitura, recitação de fábulas e contos, bem como de trabalhos manuais. Após essa etapa, houve a divisão em cinco classes, as quais compreendiam as mesmas disciplinas do itinerário curricular anterior, com acréscimo da história sagrada, que era oferecida na terceira classe; gramática e composição portuguesa e canto, na segunda classe. Encerrando esse ciclo, existia a primeira divisão, que englobava a formação em literatura, inglês, história, aritmética, piano e instrução religiosa.

Neste mesmo ano, as religiosas que já vinham apontando para a necessidade de ampliarem as dependências da escola, por conta da afluência de alunas, transferiram-se do Andaraí Grande para um palacete que havia pertencido a Antonio Clemente Pinto, situado à Rua Conde de Bonfim, 135, na Tijuca. A localização era favorecida por conta do acesso aos meios de transporte, em especial o bonde elétrico, cuja estação era próxima da nova sede do colégio. O bairro, de acordo com Brasil Gerson, possuía um perfil "tranquilo, conservador, com certo quê de aristocrático". ${ }^{27}$ Ainda para este

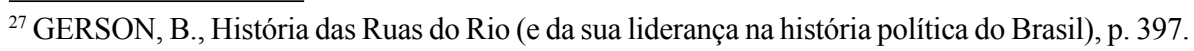


autor, do final dos oitocentos ao início do século XX, este local, que era caracterizado por chácaras, foi cedendo o espaço para palacetes, ornamentados com arquitetura refinada.

O crescimento da missão no Rio de Janeiro demandou a vinda de mais religiosas e, portanto, nos primeiros anos do século XX chegaram à cidade um novo grupo de religiosas. Tal fato revela o prestígio e reputação da qual gozavam as religiosas da congregação dos Santos Anjos. Concomitantemente, o ensino feminino religioso na capital do Brasil se consolidava, atendendo às elites conservadoras, que preocupadas com os avanços da modernidade, investiam e auxiliavam na propagação deste tipo de ensino no país.

As primeiras décadas do século XX foram marcadas pelo desenvolvimento material e técnico nacional, de modo que o Rio de Janeiro foi palco de importantes transformações urbanas. ${ }^{28}$ Foram criadas na cidade, neste período, instituições voltadas para a formação de profissões que dialogavam com as demandas impostas pela modernidade, a exemplo do Instituto Americano de Engenharia, ${ }^{29}$ do Instituto Técnico Nacional ${ }^{30}$ e do Instituto Profissional de Eletricistas, Maquinistas e Pilotos, ${ }^{31}$ localizados à Rua da Assembleia, 45; além da Escola de Aviação, R. do Rosário, 60, $2^{\circ}$ andar. ${ }^{32}$

A instrução oferecida às jovens moças, por sua vez, incorporou novas disciplinas, que dialogavam com o progresso e a modernização brasileira. A partir dos anos de 1920, o Colégio dos Santos Anjos passou a oferecer para as alunas, matérias, para além das que foram mencionadas, como: exercícios de memória, história universal, história natural, física, química, geometria, solfejo e música instrumental. Cadeiras que, paulatinamente, ampliavam o

\footnotetext{
${ }^{28}$ Existiram, entretanto, duas reformas urbanas no Rio de Janeiro entre os anos de 1903 e 1906, durante o governo de Rodrigues Alves. A primeira, empreendida pelo governo federal, que teve como ponto de partida a renovação da região portuária; e a segunda, executada no âmbito municipal, que teve como objetivo primordial o remodelamento urbano, visando integrar o centro urbano às demais regiões da cidade, segundo os ditames do progresso e da civilização. Ver: AZEVEDO, A. N., A Reforma de Pereira Passos: uma tentativa de integração urbana.

${ }^{29}$ ALMANAK LAEMMERT: administrativo, mercantil e industrial de 1914, Rio de Janeiro, p. 1023.

${ }^{30}$ ALMANAK LAEMMERT: administrativo, mercantil e industrial de 1914, Rio de Janeiro, p. 1023.

${ }^{31}$ ALMANAK LAEMMERT: administrativo, mercantil e industrial de 1914, Rio de Janeiro, p. 1023.

32 ALMANAK LAEMMERT: administrativo, mercantil e industrial de 1914, Rio de Janeiro, p. 1022 .
} 
horizonte de formação das estudantes, muito embora a essência da educação que lhes eram oferecidas se mantivesse.

\section{Conclusão}

Em síntese, a criação do Colégio dos Santos Anjos no Rio de Janeiro atendia a um movimento no interior da cristandade: o de reforçar os valores femininos segundo a reforma ultramontana. Neste sentido, a figura da mulher, enquanto mãe e esposa, se constituiu em peça fundamental na propagação dos ideais cristãos. Por essa razão, a Igreja apoiou e acolheu a chegada dessas religiosas na cidade, gerando condições para o estabelecimento da obra educacional.

A capital federal, que vivenciava a Belle Époque, estava aberta às influências europeias, nos hábitos e costumes, mas também na educação. A formação inspirada nos moldes da cultura francesa, e que era oferecida no Colégio dos Santos Anjos, ia de encontro aos anseios das elites cariocas. Tais elementos, que contribuíam para uma formação diferenciada, eram estimulados pelas oligarquias brasileiras, que buscava distinção em relação aos demais segmentos sociais. Em um contexto de progresso e modernidade, a instrução feminina passou a ser uma preocupação por parte dessas mesmas elites, no sentido de oferecer uma educação que preparasse a mulher para assumir papéis tradicionais na sociedade.

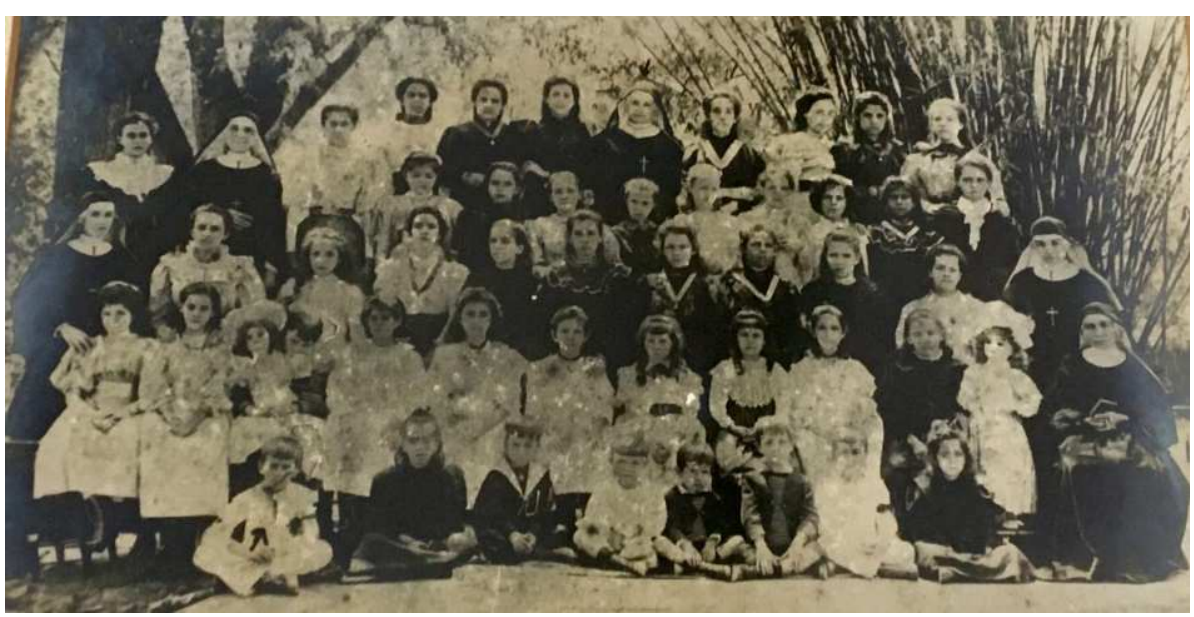

Fotografia das alunas e educadoras religiosas do Colégio dos Santos Anjos.

1898. Centro de Memória Santos Anjos, Colégio dos Santos Anjos - Rio de Janeiro. 


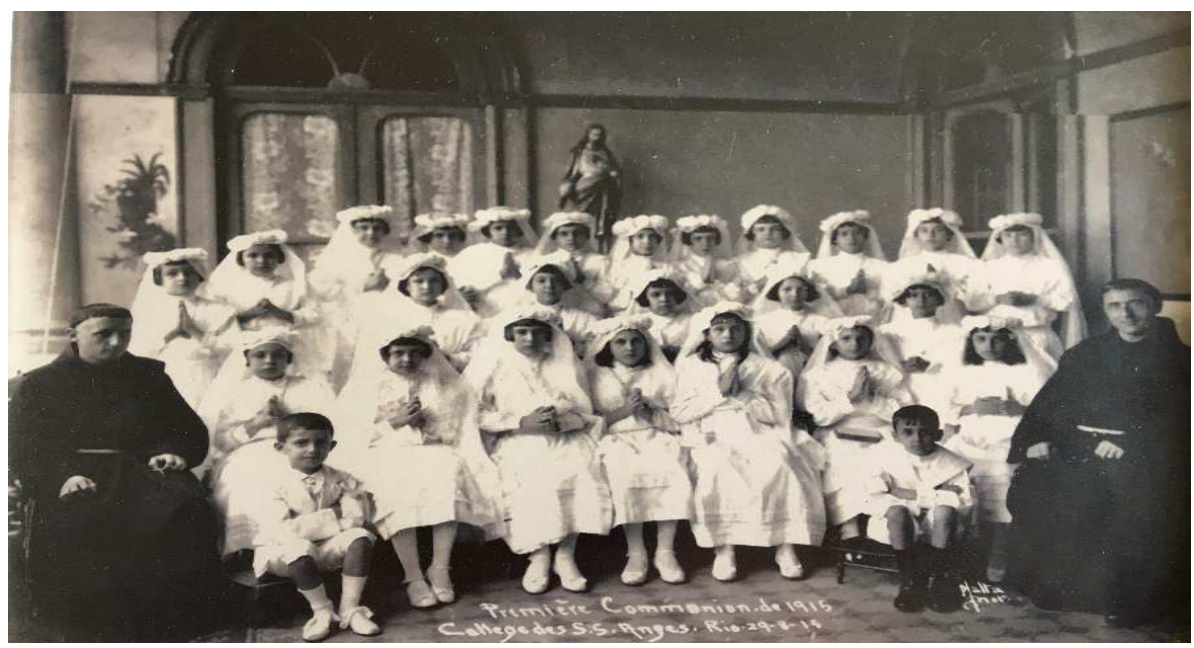

MALTA, A. Primeira Comunhão das alunas do Colégio dos Santos Anjos. 1915. Centro de Memória Santos Anjos, Colégio dos Santos Anjos - Rio de Janeiro.

\section{Referências bibliográficas}

ALMANAK LAEMMERT: administrativo, mercantil e industrial de 1914, Rio de Janeiro, p. 1023.

AZEVEDO, A. N. A Reforma de Pereira Passos: uma tentativa de integração urbana. Revista Rio de Janeiro, n. 10, mai./ago. 2003.

BLONDET, P. L. Carta para Mère Elizabeth, 10 out. 1891.

BLONDET, P. L. Carta para Mère Elizabeth, 14 dez.1891.

BLONDET, P. L. Carta para Mère Elizabeth, 15 out.1892.

BLONDET, P. L. Carta para Mère Adelaide Condamin, 17 jan. 1893.

BLONDET, P. L. Carta para Mère Adelaide Condamin, 20 jan. 1893.

BLONDET, P. L. Carta para Mère Adelaide Condamin, 10 fev. 1893.

CARDOSO, F. H. O sistema oligárquico nos primeiros anos da República. In: CARDOSO, F. H. et al. O Brasil republicano: estrutura de poder e economia (1889-1930). 8.ed. Rio de Janeiro: Bertrand Brasil, 2006. p. 17-57.

FREITAS, Ver. Pe. S. F. O Paiz, Rio de Janeiro, 24 ago. 1893. p. 2. 
GERSON, B. História das Ruas do Rio (e da sua liderança na história política do Brasil). Rio de Janeiro: Bem-Te-Vi, 2013.

GOMES, A. C. (Org). Escrita de si, escrita da história. Rio de Janeiro: FGV, 2004.

JORNAL DA FUNDAÇÃO da Comunidade de Santos Anjos no Rio de Janeiro. Santos Anjos no Rio de Janeiro: preparação e ano de 1893, Volume 01-B, Centro de Memória Santos Anjos, Colégio dos Santos Anjos - Rio de Janeiro.

JORNAL DO COMMERCIO, 14 jun. 1993. p. 4.

MALTA, Augusto. Primeira Comunhão das alunas do Colégio dos Santos Anjos. 1915. Centro de Memória Santos Anjos, Colégio dos Santos Anjos Rio de Janeiro.

MANOEL, I. A. Igreja e educação feminina. São Paulo: Editora UNESP, 1996.

MANOEL, I. A. O início da educação católica feminina no Brasil (18591919): os colégios das “freiras francesas". Pág. Educ., v. 5, n. 1, p. 115-134, 2012.

MAYEUR, J.-M. Les débuts de la IIIe République (1871-1898). Paris: Éditions du Seuil, 1973.

NEEDELL, J. Belle époque tropical: sociedade e cultura de elite no Rio de Janeiro na virada do século. São Paulo: Companhia das Letras, 1993.

RODRIGUES, A. E. M. R. A costura da cidade: a construção da mobilidade carioca. Rio de Janeiro: Bazar do Tempo, 2016.

Giselle Pereira Nicolau

Doutora em História pela Universidade Federal Fluminense

Rio de Janeiro / RJ - Brasil

E-mail: giselle.histoire@gmail.com

Recebido em: 19/10/2021

Aprovado em: 25/11/2021 